\title{
Mananoligossacarídeos e complexo enzimático em dietas para frangos de corte $^{1}$
}

\section{Maria Cristina de Oliveira ${ }^{2}$, Luciana Cardoso Cancherini ${ }^{3}$, Rafael Henrique Marques ${ }^{3}$, Rodrigo Antônio Gravena ${ }^{3}$, Vera Maria Barbosa de Moraes $^{3}$}

\author{
${ }^{1}$ Pesquisa financiada pela Fundação de Apoio à Pesquisa do Estado de São Paulo (FAPESP), Alltech do Brasil e Fundação para o \\ Desenvolvimento da Unesp (FUNDUNESP). \\ ${ }^{2}$ Faculdade de Medicina Veterinária, Universidade de Rio Verde - FESURV, Rio Verde, GO. \\ ${ }^{3}$ Faculdade de Ciências Agrárias e Veterinária, UNESP, Jaboticabal, SP.
}

RESUMO - Avaliou-se o efeito de dietas com mananoligossacarídeos e complexo enzimático (CE) sobre o desempenho, a morfologia intestinal e a qualidade da cama de frangos aos 42 dias de idade. Foram utilizadas 750 aves em delineamento inteiramente casualizado em esquema fatorial $2 \times 2+1$, com dois níveis de mananoligossacarídeos $(0$ e $0,1 \%$ de 1 a 21 dias e $0,05 \%$ de 22 a 42 dias de idade), dois níveis de complexo enzimático (0 e 0,05\%) e uma dieta com antibióticos (CP), totalizando cinco dietas com cinco repetições. Aos 42 dias de criação, o desempenho foi avaliado e, após o abate das aves, foram coletadas amostras de intestino e de cama e avaliado o desempenho. A inclusão de mananoligossacarídeos e/ou complexo enzimático na dieta não afetou o desempenho das aves, o perímetro e a altura dos vilos duodenais, a profundidade de criptas, a densidade de vilos no duodeno, jejuno e íleo, os teores de matéria seca e nitrogênio total e o pH das camas. A interação mananoligossacarídeos $\times$ complexo enzimático foi significativa para perímetro e altura de vilos no jejuno, que foram maiores nas aves alimentadas com as rações sem complexo enzimático e mananoligossacarídeos, mesmo comportamento observado para perímetro e altura de vilos ileais. Entretanto, quando adicionados mananoligossacarídeos e complexo enzimático, os valores dessas variáveis reduziram. A volatilização de amônia aumentou em camas de frango tratados com antibióticos e diminuiu com a adição de mananoligossacarídeos à dieta. A adição de mananoligossacarídeos ou complexo enzimático às dietas aumentou o perímetro e altura de vilos da mucosa do jejuno e do íleo e reduziu a volatilização de amônia da cama.

Palavras-chave: enzimas, morfologia intestinal, prebiótico

\section{Mannan oligosaccharides and enzymatic complex in broiler diets}

\begin{abstract}
The effect of diets with mannan oligosaccharides (MOS) and enzymatic complex (EC) on performance, intestinal morphology and litter quality of 42-day-old broilers was evaluated. Seven hundred and fifty birds were used in a completely randomized design and $2 \times 2+1$ factorial arrangement, with two MOS levels $(0$ and $0.1 \%$ from 1 to 21 days of age and $0.05 \%$ from 22 to 42 days of age), two EC levels ( 0 and $0.05 \%$ ) and a diet with antibiotics (PC), totaling five treatments with five replicates. At 42 days of age, the performance was evaluated, and after slaughter, intestinal and litter samples were collected. MOS and/or EC inclusion did not affect the performance, perimeter and height of duodenal villi, crypt depth and villi density in duodenum, jejunum and ileum, and dry matter and total nitrogen content and $\mathrm{pH}$ of the litters. The MOS $\times$ EC interaction was significant to villi perimeter and height in jejunum, and birds submitted to diets without EC and with MOS showing higher values. The same behavior was observed to villi perimeter and height in ileum. However, when MOS and EC were added to diets, the values were lower for these variables. Ammonia volatilization increased in litter of broilers treated with antibiotics and decreased when MOS were added to diet. The inclusion of MOS and EC in the diets increased the villi perimeter and height in jejunum and ileum and decreased the ammonia volatilization of litters.
\end{abstract}

Key Words: enzymes, intestinal morphology, prebiotic

\section{Introdução}

Antibióticos controlam o crescimento de bactérias patogênicas e não-patogênicas intestinais (Ferket et al.,
2002). Os mananoligossacarídeos (MOS) removem patógenos (Patterson \& Burkholder, 2003) e modificam a flora intestinal, reduzem o tumover da mucosa, modulam o sistema imune (Shane, 2001), melhoram o desempenho 
(Sims et al., 2004) de frangos e aumentam a altura de vilos (Iji et al., 2001) intestinais. Ao avaliar o uso de avilamicina e MOS, Schwarz et al. (2002) não notaram diferenças na altura de vilos e profundidade de cripta, porém, utilizando bacitracina e MOS, Sims et al. (2004) verificaram que aves alimentadas com dietas contendo antibiótico apresentaram vilos maiores.

O milho e o farelo de soja apresentam polissacarídeos não-amiláceos (PNA) (Alam et al., 2003) e o uso de enzimas exógenas compensa o reduzido desempenho animal, devido à restrição ao uso de antibióticos nas dietas (Thorpe $\&$ Beal, 2001), reduz a variação na qualidade nutricional dos ingredientes e a incidência de cama úmida (Bedford, 2000). Os polissacarídeos nãoamiláceos inolúveis são diluentes de nutrientes, afetam o tempo de trânsito da digesta e a motilidade intestinal e são barreiras físicas à ação das enzimas digestivas (Choct, 2001).

Em aves de 4 a 21 dias de idade, o volume de vilos e a profundidade de cripta aumentam, mas ocorre pouca alteração na densidade dos enterócitos (Uni et al., 1998). Os enterócitos proliferam na cripta intestinal e a profundidade da cripta está relacionada à substituição celular, acelerada pela ingestão ou produção de compostos deletérios, incluindo amônia, pela flora intestinal (Shane, 2001). Segundo Choct (2001), dieta contendo 75 g de polissacarídeo não-celulósico e $24 \mathrm{~g}$ de celulose/kg induziu maior síntese protéica no jejuno e íleo e a divisão das células da mucosa mais rápida do que em ratos que ingeriram celulose como fonte de PNA.

Frangos são criados sobre camas reutilizadas e, para manter doenças sob controle, coccidiostáticos e antibióticos são usados (Hooge et al., 2003). Polissacarídeos nãoamiláceos na dieta são associados à maior consumo de água e de umidade nas fezes das aves (Francesch \& Brufau, 2004). Kocher et al. (2000), entretanto, utilizaram as enzimas celulase, $\beta$-glucanase, $\beta$-xilanase e pectinase na dieta de frangos de 7 a 28 dias de idade e relataram que o teor de umidade das excretas não foi influenciado.

Avaliou-se efeito da adição de MOS e complexo enzimático (CE) à dieta sobre o desempenho, morfologia da mucosa intestinal e qualidade da cama de frangos de corte.

\section{Material e Métodos}

Foram utilizados 750 pintos de 1 dia, linhagem Cobb e com peso inicial médio de 41,51 $\pm 0,59 \mathrm{~g}$. O delineamento foi inteiramente casualizado em arranjo fatorial $2 \times 2+1 \mathrm{com}$ dois níveis de mananoligossacarídeos ( 0 e 0,1\% de 1 a 21 dias e $0,05 \%$ de 22 a 42 dias de idade), dois níveis de complexo enzimático (0 e 0,05\%) e uma dieta controle positivo (125 ppm de sulfato de colistina e $10 \mathrm{ppm}$ de virginiamicina), totalizando cinco dietas e cinco repetições.

A fitase, com atividade mínima de $250 \mathrm{U} / \mathrm{g}$, foi utilizada em todas as dietas e o nível de fósforo não-fítico utilizado foi de $0,38 \%$, correspondendo a $85 \%$ das exigências da ave. O complexo enzimático, na forma líquida, consistiu de celulase, protease e $\alpha$-amilase e foi pré-misturado a $500 \mathrm{~g}$ de farelo de soja antes de os ingredientes serem colocados no misturador.

As dietas experimentais (Tabelas 1 e 2 ) foram formuladas conforme descrito por Rostagno et al. (2000) e eram isonutritivas, exceto pela energia metabolizável e pela proteína bruta, que corresponderam a 98\% dos níveis nutricionais descritos pelos mesmos autores. Tanto a água quanto as dietas foram fornecidas à vontade durante todo o período experimental.

Quando as aves atingiram 42 dias de idade, o ganho de peso, o consumo de ração, a conversão alimentar e a viabilidade foram avaliados. Após 12 horas de jejum alimentar, cinco aves por tratamento foram sacrificadas por deslocamento cervical e duas amostras ( $2 \mathrm{~cm}$ cada uma) foram retiradas na metade do comprimento da alça duodenal, a $10 \mathrm{~cm}$ acima do divertículo de Meckel (jejuno) e $10 \mathrm{~cm}$ acima da junção ileocecal (íleo) de cada ave. Uma amostra foi processada para microscopia de luz (fixada em Bouin por 24 horas) e a outra para microscopia eletrônica de varredura (fixadas em glutaraldeído 3\% por 48 horas). Foram realizadas 40 leituras/amostra para análise do perímetro e da altura de vilo e profundidade de cripta. A contagem do número de células caliciformes foi realizada em uma área de $1 \mathrm{~mm}^{2}$. A densidade de vilos foi determinada também em uma área de $1 \mathrm{~mm}^{2}$ utilizando-se microfotografias de três áreas diferentes da mesma amostra, utilizando sempre o mesmo aumento de 75 vezes.

O material utilizado como cama em todos os tratamentos era composto de maravalha (22 kg de matéria natural/box) e teor de matéria seca inicial de 89,90\%. Quando as aves completaram 42 dias de idade, amostras da cama foram coletadas, em seis pontos do box, evitando-se áreas próximas e embaixo do bebedouro e comedouro. Posteriormente, as amostras foram analisadas para determinação da quantidade de amônia volatilizada (Oliveira et al., 2004), teor de matéria seca, nitrogênio total e fósforo (Silva \& Queiroz, 2002) e do $\mathrm{pH}$.

Os resultados obtidos foram submetidos à ANOVA e as médias do fatorial mananoligossacarídeos $\times$ complexo enzimático foram comparadas pelo teste de Fischer e as médias do controle positivo $\times$ fatorial, pelo teste Dunnett (Statsoft, 1995). 


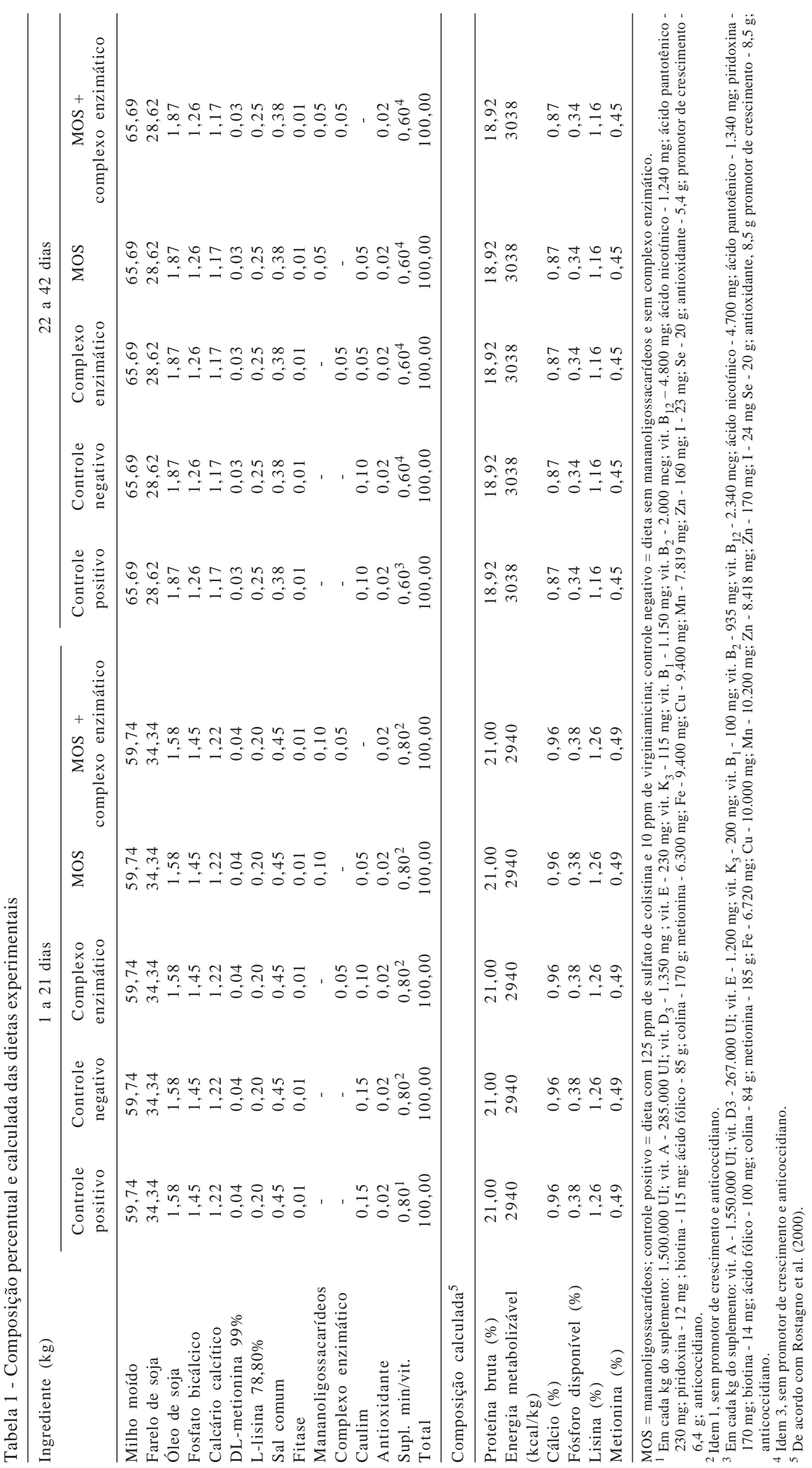


Tabela 2 - Desempenho de frangos de corte de 1 a 42 dias alimentados com rações com mananoligossacarídeos e/ou complexo enzimático (CE)

\begin{tabular}{|c|c|c|c|c|c|c|}
\hline \multirow[t]{2}{*}{ Parâmetro } & \multirow[t]{2}{*}{ Controle positivo } & \multirow[t]{2}{*}{ Mananoligossacarídeos } & \multicolumn{2}{|c|}{ Complexo enzimático (\%) } & \multirow[t]{2}{*}{ Média } & \multirow[t]{2}{*}{ CV (\%) } \\
\hline & & & Sem & Com & & \\
\hline \multirow[t]{3}{*}{ Ganho de peso (g) } & & Sem & 2.687 & 2.715 & 2.701 & \\
\hline & & Com & 2.723 & 2.676 & 2.699 & \\
\hline & 2.684 & Média & 2.705 & 2.696 & & 2,32 \\
\hline \multirow[t]{3}{*}{ Consumo de ração (g) } & & Sem & 4.691 & 4.653 & 4.672 & \\
\hline & & Com & 4.673 & 4.517 & 4.595 & \\
\hline & 4.570 & Média & 4.682 & 4.585 & & 2,74 \\
\hline \multirow[t]{3}{*}{ Conversão alimentar } & & Sem & 1,75 & 1,71 & 1,73 & \\
\hline & & Com & 1,72 & 1,70 & 1,70 & \\
\hline & 1,70 & Média & 1,73 & 1,70 & & 2,69 \\
\hline \multirow[t]{3}{*}{ Viabilidade (\%) } & & Sem & 99,34 & 97,33 & 98,33 & \\
\hline & & Com & 100,00 & 99,97 & 99,33 & \\
\hline & 98,67 & Média & 99,33 & 98,33 & & 1,96 \\
\hline
\end{tabular}

$\mathrm{CP}=$ controle positivo; $\mathrm{CV}$ = coeficiente de variação.

\section{Resultados e Discussão}

Não houve diferença $(\mathrm{P}>0,05)$ nos resultados de desempenho entre os níveis de complexo enzimático e mananoligossacarídeos (Tabela 2). O milho e o farelo de soja são ingredientes de alto valor nutritivo, portanto, é possível que a redução nos níveis de proteína bruta e energia metabolizável não tenha sido suficiente para que os mananoligossacarídeos e o complexo enzimático tivessem efeito maior. Além disso, as boas condições de alojamento a que as aves foram submetidas podem ter colaborado para a ausência de desafio e, conseqüentemente, de diferença nos resultados de desempenho.

Waldroup et al. (2003) e Sims et al. (2004) também relataram não haver diferenças no desempenho de frangos aos 42 dias de idade atribuídas ao uso de mananoligossacarídeos ou antibióticos nas dietas. Flemming et al. (2004), no entanto, utilizaram 0,05\% de mananoligossacarídeos em dietas para frangos e observaram que o ganho de peso diário diminuiu em relação ao tratamento controle, enquanto Hooge et al. (2003) testaram a inclusão de 0,1 e 0,5\% de mananoligossacarídeos e 55 e 27,5 ppm de bacitracina para frangos e notaram melhora no peso final e na conversão alimentar em comparação às aves mantidas com dietas sem antibióticos.

Resultados semelhantes com o uso de enzimas foram obtidos por Pinheiro et al. (2004), que estudaram o uso de enzimas como protease, $\alpha$-amilase e celulase, entre outras em dieta à base de milho e de farelo de soja. Esonu et al. (2004), no entanto, incluíram celulase em dietas para frangos de 28 a 35 dias de idade e constataram que o ganho de peso diminuiu e o consumo de ração aumentou com a inclusão da

Tabela 3 - Morfometria e número de células caliciformes e vilos no duodeno de frangos alimentados com rações com mananoligossacarídeos e/ou complexo enzimático

\begin{tabular}{|c|c|c|c|c|c|c|}
\hline Parâmetro & Controle positivo & Mananoligossacarídeos & \multicolumn{2}{|c|}{ Complexo enzimático (\%) } & Média & CV (\%) \\
\hline \multirow[t]{2}{*}{ Perímetro de vilo $(\mu \mathrm{m})$} & & Sem & 2.813 & 2.763 & 2.881 & \\
\hline & 3.072 & Média & 2.907 & 2.839 & & 11,82 \\
\hline \multirow[t]{2}{*}{ Altura de vilo $(\mu \mathrm{m})$} & & Sem & 1.419 & 1.364 & 1.391 & \\
\hline & & Com & 1.495 & 1.481 & 1.488 & \\
\hline \multirow{2}{*}{\multicolumn{2}{|c|}{ Profundidade de cripta $(\mu \mathrm{m})$}} & Sem & 136 & 116 & 126 & \\
\hline & & Com & 142 & 130 & 136 & \\
\hline & 142 & Média & 139 & 123 & & 18,46 \\
\hline \multirow[t]{2}{*}{ Número de vilos $/ \mathrm{mm}^{2}$} & & Sem & 12,25 & 10,90 & 11,58 & \\
\hline & & Com & 11,22 & 12,24 & 11,73 & \\
\hline
\end{tabular}

$\mathrm{CV}=$ coeficiente de variação. 
enzima, mas não houve diferença no peso final e na conversão alimentar. Segundo Gracia et al. (2003), aves alimentadas com rações contendo $\alpha$-amilase consumiram mais ração e foram mais pesadas, mas não houve diferença na conversão alimentar. Comparando dietas com níveis de proteína bruta e energia metabolizável normais e reduzidos em $3 \%$ e suplementadas ou não com $\alpha$-amilase, protease e xilanase, Córtes et al. (2002) notaram que as aves que ingeriram a ração sem enzimas apresentaram menor peso corporal e pior conversão alimentar.

Ao estudarem o uso associado de prebiótico e complexo enzimático (protease, celulase, amilase, fitase, entre outras) em dietas para frangos de 1 a 42 dias, Kirkpinar et al. (2004) verificaram que, embora não tenha havido diferenças no consumo de ração, os frangos alimentados com rações contendo os dois aditivos apresentaram maior peso.

Os resultados de perímetro e altura de vilos duodenais (Tabela 3), profundidade de cripta e densidade de vilos no duodeno, jejuno (Tabela 4) e íleo (Tabela 5), bem como o número de células caliciformes duodenais e ileais, não foram influenciados $(\mathrm{P}>0,05)$ pelos tratamentos.

Houve efeito da interação $(\mathrm{P}<0,03)$ mananoligossacarídeos $\times$ enzimas sobre o perímetro e a altura de vilos e o número de células caliciformes no jejuno e sobre o perímetro $(\mathrm{P}<0,01)$ e a altura $(\mathrm{P}<0,01)$ de vilos ileais. $\mathrm{O}$ número de células caliciformes aumentou no jejuno com a inclusão do mananoligossacarídeos e/ou das enzimas, provavelmente em resposta ao aumento da altura e perímetro de vilos. Como houve redução de 50\% na quantidade de

Tabela 4 - Morfometria e número de células caliciformes e vilos no jejuno de frangos alimentados com rações com mananoligossacarídeos e/ou complexo enzimático

\begin{tabular}{|c|c|c|c|c|c|c|}
\hline \multirow[t]{2}{*}{ Parâmetro } & \multirow[t]{2}{*}{ Controle positivo } & \multirow[t]{2}{*}{ Mananoligossacarídeos } & \multicolumn{2}{|c|}{ Complexo enzimático (\%) } & \multirow[t]{2}{*}{ Média } & \multirow[t]{2}{*}{ CV (\%) } \\
\hline & & & Sem & Com & & \\
\hline \multirow[t]{3}{*}{ Perímetro de vilo $(\mu \mathrm{m})$} & & Sem & $2.393 \mathrm{Bb}$ & $2.821 \mathrm{Aa}$ & 2.607 & \\
\hline & & Com & $2.817 \mathrm{Aa}$ & $2.589 \mathrm{Aa}$ & 2.703 & \\
\hline & 2.518 & Média & 2.605 & 2.705 & & 10,65 \\
\hline \multirow[t]{3}{*}{ Altura de vilo $(\mu \mathrm{m})$} & & Sem & $1.174 \mathrm{Bb}$ & $1.393 \mathrm{Aa}$ & 1.284 & \\
\hline & & Com & $1.402 \mathrm{Aa}$ & $1.302 \mathrm{Aa}$ & 1.352 & \\
\hline & 1.236 & Média & 1.288 & 1.347 & & 10,43 \\
\hline \multirow{2}{*}{\multicolumn{2}{|c|}{ Profundidade de cripta $(\mu \mathrm{m})$}} & Sem & 111 & 113 & 112 & \\
\hline & & Com & 117 & 112 & 115 & \\
\hline & 102 & Média & 114 & 113 & & 17,03 \\
\hline \multirow[t]{3}{*}{ Número de vilos $/ \mathrm{mm}^{2}$} & & Sem & 17,52 & 14,58 & 16,05 & \\
\hline & & Com & 18,43 & 18,13 & 18,28 & \\
\hline & 18,72 & Média & 17,97 & 16,35 & & 17,97 \\
\hline
\end{tabular}

$\mathrm{CV}=$ coeficiente de variação.

Médias seguidas por letras diferentes maiúsculas nas colunas e minúsculas nas linhas diferem entre si pelo teste Tukey.

Tabela 5 - Morfometria e número de células caliciformes e vilos no íleo de frangos alimentados com rações com mananoligossacarídeos e/ou complexo enzimático

\begin{tabular}{|c|c|c|c|c|c|c|}
\hline \multirow[t]{2}{*}{ Parâmetro } & \multirow[t]{2}{*}{ Controle positivo } & \multirow[t]{2}{*}{ Mananoligossacarídeos } & \multicolumn{2}{|c|}{ Complexo enzimático (\%) } & \multirow[t]{2}{*}{ Média } & \multirow[t]{2}{*}{ CV (\%) } \\
\hline & & & Sem & Com & & \\
\hline \multirow[t]{2}{*}{ Perímetro de vilo $(\mu \mathrm{m})$} & & Sem & $1.713 \mathrm{Ba}$ & $1.904 \mathrm{Aa}$ & 1.808 & \\
\hline & 1747 & Média & 1.880 & 182 & & 11,30 \\
\hline \multirow[t]{2}{*}{ Altura de vilo $(\mu \mathrm{m})$} & & Sem & $826 \mathrm{Ba}$ & 918Аа & 872 & \\
\hline & & Com & 993Aa & $801 \mathrm{Ab}$ & 893 & \\
\hline \multirow[t]{3}{*}{ Profundidade de cripta $(\mu \mathrm{m}$} & & Sem & 112 & 102 & 10 & \\
\hline & & Com & 114 & 102 & 108 & \\
\hline & 107 & Média & 113 & 103 & & 13,13 \\
\hline \multirow[t]{3}{*}{ Número de vilos/mm² } & & Sem & 26,42 & 26,55 & 26,49 & \\
\hline & & Com & 25,84 & 26,90 & 26,37 & \\
\hline & 26,15 & Média & 26,13 & 26,72 & & 17,02 \\
\hline
\end{tabular}

CV = coeficiente de variação.

Médias seguidas por letras diferentes maiúsculas nas colunas e minúsculas nas linhas diferem entre si pelo teste Tukey. 
mananoligossacarídeos adicionada à dieta na fase de crescimento é possível que a fermentação e produção de ácidos graxos de cadeia curta tenha também sido baixa no duodeno e só alcançado valores significativos no jejuno e íleo.

Os ácidos graxos de cadeia curta são eficazes em estimular o desenvolvimento da mucosa intestinal porque servem de fonte de energia para os enterócitos e permitem que bactérias benéficas proliferem, produzam mais ácidos graxos de cadeia curta e reduzam o $\mathrm{pH}$ do microambiente da borda em escova e/ou bloqueiem a adesão de patógenos (Ferket, 2004) e estes efeitos promovem melhor desenvolvimento do epitélio intestinal. As enzimas estimulam a mucosa intestinal por reduzirem a quantidade de substrato disponível para degradação bacteriana, pois menor quantidade de substrato resulta em menor quantidade de bactérias. As aves que ingeriram rações sem aditivos (controle negativo) tiveram, possivelmente, maior carga bacteriana no intestino, o que pode ter causado a redução no perímetro e altura de vilosidades por danos à mucosa, tanto no jejuno quanto no íleo. No íleo, ocorreu redução no perímetro e na altura de vilos quando os mananoligossacarídeos e as enzimas foram adicionados às dietas, provavelmente em virtude do aumento da digestibilidade dos nutrientes nesta região do intestino, causado pela associação dos dois aditivos.

O crescimento e a colonização de bactérias nãopatogênicas no intestino são limitados pelos antibióticos promotores de crescimento. A redução, principalmente de lactobacilos e bifidobactérias, diminui a produção de ácidos graxos voláteis que estimulam o crescimento do epitélio intestinal. Como conseqüência, o pH intestinal aumenta favorecendo o desenvolvimento de bactérias patogênicas (Edens et al., 1997) que podem danificar a mucosa intestinal. Segundo Van Leeuwen (2002), menor altura e perímetro de vilos em aves alimentadas com rações contendo antibióticos indica que houve reduzido turnover do epitélio intestinal, possivelmente em virtude da atividade bacteriana suprimida.

Sims et al. (2004) trabalharam com dietas contendo 0,1\% de mananoligossacarídeos e $55 \mathrm{mg} / \mathrm{kg}$ de bacitracina até a 6 a semana e $0,05 \%$ de mananoligossacarídeos e $27,5 \mathrm{mg} / \mathrm{kg}$ de bacitracina $7 \underline{\text { a }}$ a 18 a semana de idade e notaram que perus tratados com bacitracina tiveram vilos mais longos em todo o intestino na $18^{\mathrm{a}}$ semana. Schwarz et al. (2002), no entanto, compararam os efeitos de dietas com e sem antibiótico e com frutoligossacarídeo $(0,2 \%)$ e mananoligossacarídeos $(0,2 \%)$ e não constataram diferenças na altura dos vilos e na profundidade das criptas no jejuno.
Yasar \& Forbes (2000) estudaram a adição de xilanase, protease e $\beta$-glucanase em dietas para frangos e não observaram diferenças na altura dos vilos, na profundidade das criptas e no número de criptas por vilo no intestino delgado e Brenes et al. (2002) avaliaram três complexos multienzimáticos em dietas à base de tremoço para frangos de 1 a 42 dias de idade e notaram que os pesos relativos do duodeno, jejuno e íleo foram menores nas aves alimentadas com rações contendo um dos complexos enzimáticos ou uma mistura deles. Os autores associaram este fato à redução no número de bactérias presentes no intestino delgado, ocasionado pela redução na quantidade de substratos disponíveis para as bactérias.

Houve efeito da interação antibiótico $\times$ fatorial $(\mathrm{P}<0,03)$ sobre a qualidade da cama, pois verificou-se aumento de 72 a 167\% na volatilização de amônia das camas de frangos alimentados com ração contendo antibióticos e a inclusão de prebiótico diminuiu $(\mathrm{P}<0,03)$ a volatilização de amônia em 30,73\% (Tabela 6).

A maior quantidade de amônia volatilizada da cama de frangos submetidos à dieta com antibióticos ocorreu, provavelmente porque os antibióticos não atuaram sobre as bactérias produtoras de amônia, fato relatado por Bongaerts et al. (2005) em estudos com seres humanos. A redução na volatilização de amônia com a adição de mananoligossacarídeos à dietas possivelmente ocorreu porque, de acordo com Choct \& Kocher (2000), carboidratos de baixo peso molecular como os oligossacarídeos são completamente digeridos no intestino grosso e a conseqüência é o aumento no número de Lactobacilli e Bifidobacterium e a redução em Clostridia $e$ Enterobacteria, que produzem amônia. Aumento no número de Lactobacillus e Bifidobacterium atribuído ao uso de mananoligossacarídeos na dieta de frangos foi relatado também por Fernandez et al. (2002). Além disso, essas bactérias competem por substratos, inibindo o crescimento de bactérias de outros gêneros e reduzindo a quantidade de nitrogênio não-protéico, o que, segundo Chang \& Chen (2003), pode reduzir a concentração de amônia no ambiente, o pH e a umidade das excretas de frangos. Zentek et al. (2002) verificaram efeito semelhante em cães, com redução do pH e da concentração de amônia fecal com o uso de mananoligossacarídeos em comparação ao uso de lactose, lactulose, transgalactoligossacarídeo e antibiótico. Zdunczyk et al. (2004) relataram que o uso de mananoligossacarídeos ou inulina na dieta de frangos de corte não afetou o teor de matéria seca e a volatilização de amônia em comparação a camas de frangos alimentados com dietas com ou sem flavomicina. 
Tabela 6 - Características da cama de frangos alimentados com rações com mananoligossacarídeos e/ou complexo enzimático

\begin{tabular}{|c|c|c|c|c|c|c|}
\hline \multirow[t]{2}{*}{ Parâmetro } & \multirow[t]{2}{*}{ Controle positivo } & \multirow[t]{2}{*}{ Mananoligossacarídeos } & \multicolumn{2}{|c|}{ Complexo enzimático (\%) } & \multirow[t]{2}{*}{ Média } & \multirow[t]{2}{*}{ CV (\%) } \\
\hline & & & Sem & Com & & \\
\hline \multirow[t]{3}{*}{ Matéria seca (\%) } & & Sem & 72,95 & 72,57 & 72,76 & \\
\hline & & Com & 72,72 & 74,07 & 73,40 & \\
\hline & 72,32 & Média & 72,84 & 73,32 & & 2,96 \\
\hline \multirow[t]{3}{*}{ Nitrogênio total $(\%)^{1}$} & & Sem & 3,26 & 3,10 & 3,18 & \\
\hline & & Com & 3,08 & 3,07 & 3,07 & \\
\hline & 2,95 & Média & 3,17 & 3,08 & & 9,56 \\
\hline \multirow[t]{3}{*}{$\mathrm{pH}$} & & Sem & 7,90 & 7,69 & 7,79 & \\
\hline & & Com & 7,74 & 7,76 & 7,75 & \\
\hline & 7,99 & Média & 7,82 & 7,72 & & 3,83 \\
\hline \multirow[t]{3}{*}{ Amônia volatilizada (ppm) } & & Sem & $14,10 *$ & $14,08 *$ & $14,09 a$ & \\
\hline & & Com & $9,09 *$ & $10,43^{*}$ & $9,76 b$ & \\
\hline & 24,25 & Média & 11,59 & 12,25 & & 14,19 \\
\hline \multirow[t]{3}{*}{ Fósforo total $(\%)^{1}$} & & Sem & 0,96 & 0,96 & 0,96 & \\
\hline & & Com & 0,97 & 0,94 & 0,96 & \\
\hline & 0,97 & Média & 0,96 & 0,95 & & 6,88 \\
\hline
\end{tabular}

${ }^{1}$ Com base na matéria seca; CV = coeficiente de variação.

* Difere da média do tratamento controle positivo pelo teste Dunnett.

Médias seguidas por letras diferentes diferem entre si pelo teste $\mathrm{F}$.

\section{Conclusões}

A adição de mananoligossacarídeos ou complexo enzimático às dietas melhorou o perímetro e altura de vilos intestinais e o uso mananoligossacarídeos ainda reduziu a volatilização de amônia da cama, porém o efeito dos dois aditivos não foi suficiente para melhorar o desempenho das aves.

\section{Literatura Citada}

ALAM, M.J.; HOWLIDER, M.A.R.; PRAMANIK, M.A.H. et al. Effect of exogenous enzyme in diet on broiler performance. International Journal of Poultry Science, v.2, n.2, p.168173, 2003.

BEDFORD, M.R. Exogenous enzymes in monogastric nutrition their current value and future benefits. Animal Feed Science and Technology, v.86, n.1, p.1-13, 2000.

BONGAERTS, G.; SEVERIJNEN, R.; TIMMERMAN, H. Effect of antibiotics, prebiotics and probiotics in treatment for hepatic encephalopathy. Medical Hypotheses, v.64, n.1, p.64-68, 2005.

BRENES, A.; MARQUARDT, R.R.; GUENTER, W. et al. Effect of enzyme addition on the performance and gastrointestinal tract size of chicks fed lupin seed and their fractions. Poultry Science, v.81, n.5, p.670-678, 2002.

CHANG, M.H.; CHEN, T.C. Reduction of broiler house malodor by direct feeding of a Lactobacilli containing probiotic. International Journal of Poultry Science, v.2, n.5, p.313-317, 2003.

CHOCT, M. Enzyme supplementation of poultry diets based on viscous cereals. In: BEDFORD, M.R.; PARTRIDGE, G.G. (Eds) Enzymes in farm animal nutrition. Wallingford: CabiPublishing, 2001. p.145-160.

CHOCT, M.; KOCHER, A. Non-starch carbohydrates: digestion and its secondary effects in monogastrics. ANNUAL NUTRITION SOCIETY OF AUSTRALIA SCIENTIFIC
Meeting, 24., 2000, Fremantle. Proceedings... Fremantle: NSA, 2000. p.31-38.

CORTÉS, C.A.; ÁGUILA, S.R.; ÁVILA, GE. The use of enzymes as additives in broiler chicks diets. Veterinária en México, v.32, n.1, p.1-9, 2002.

EDENS, F.W.; PARKHURST, C.R.; CASAS, I.A. et al. Principles of ex ovo competitive exclusion and in ovo administration of Lactobacillus reuteri. Poultry Science, v.76, n.1, p.179196, 1997.

ESONU, B.O.; AZUBUIKE, J.C.; EMENALOM, O.O. et al. Effect of enzyme supplementation on the performance of broiler finisher fed Microdesmis puberula leaf meal. International Journal of Poultry Science, v.3, n.2, p.112-114, 2004.

FERKET, P.R. Alternatives to antibiotics in poultry production: responses, practical experience and recommendations. In: ALLTECH'S ANNUAL SYMPOSIUM, 20., 2004, Lexington. Proceedings... Lexington: Alltech, 2004. p.54-67.

FERKET, P.R.; PARKS, C.W.; GRIMES, J.L. Benefits of dietary antibiotic and mannanoligosaccharide supplementation for poultry. In: MULTI-STATE POULTRY FEEDING AND NUTRITION CONFERENCE, 2002, Indianapolis. Proceedings... Indianapolis: University of Illinois, 2002. p.14-16.

FERNANDEZ, F.; HINTON, M.; van GILS, B. Dietary mannanoligosaccharides and their effect on chicken caecal microflora in relation to Salmonella enteritidis colonization. Avian Pathology, v.31, n.1, p.49-58, 2002.

FLEMMING, J.S.; FREITAS, J.R.S.; FONTOURA, P. et al. Use of mannanoligosaccharides in broiler feeding. Brazilian Journal of Poultry Science, v.6, n.3, p.159-161, 2004.

FRANCESCH, M.; BRUFAU, J. Nutritional factors affecting excreta/ litter moisture and quality. World Poultry Science Journal, v.60, n.1, p.64-75, 2004.

GRACÍA, M.I.; ARANÍBAR, M.J.; LÁZARO, R. et al. $\alpha$-amylase supplementation of broiler diets based on corn. Poultry Science, v.82, n.3, p.436-442, 2003.

HOOGE, D.M.; SIMS, M.D.; SEFTON, A.E. et al. Effect of dietary mannan oligosaccharide, with or without bacitracin or virginiamycin, on live performance of broiler chickens at relatively high stocking density on new litter. Journal of Applied Poultry Research, v.12, n.4, p.431-467, 2003. 
IJI, P.A.; SAKI, A.A.; TIVEY, D.R. Intestinal development and body growth of broiler chicks on diets supplemented with nonstarch polysaccharides. Animal Feed Science and Technology, v.89, n.1, p.175-188, 2001.

KIRKPINAR, F.; AÇIKGÖZ, Z.; BOZKURT, M. et al. Effects of inclusion of poultry by-product meal and enzyme-prebiotic supplementation in grower diets on performance and feed digestibility of broilers. British Poultry Science, v.45, n.2, p.273-279, 2004.

KOCHER, A.; CHOCT, M.; PORTER, M.D. et al. The effects of enzyme addition to broiler diets containing high concentrations of canola or sunflower meal. Poultry Science, v.79, n.12, p.1767-1774, 2000.

OLIVEIRA, M.C.; FERREIRA, H.A.; CANCHERINI, L.C. Efeito de condicionadores químicos sobre a qualidade da cama de frango. Arquivo Brasileiro de Medicina Veterinária e Zootecnia, v.56, n.4, p.536-541, 2004.

PATTERSON, J.A.; BURKHOLDER, K.M. Application of prebiotics and probiotics in poultry production. Poultry Science, v.82, n.4, p.627-631, 2003.

PINHEIRO, D.F.; CRUZ, V.C.; SARTORI, J.R. et al. Effect of early feed restriction and enzyme supplementation on digestive enzyme activities in broilers. Poultry Science, v.83, n.9, p.1544-1550, 2004.

ROSTAGNO, H.S.; ALBINO, L.F.T.; DONZELE, J.L. et al. Tabelas brasileiras para aves e suínos: composição de alimentos e exigências nutricionais. Viçosa, MG: Editora UFV, 2000. 141p.

SCHWARZ, K.K.; FRANCO, S.G.; FEDALTO, L.M. et al. Efeitos de antimicrobianos, probióticos, prebióticos e simbióticos sobre o desempenho e morfologia do jejuno de frangos. CONFERÊNCIA APINCO DE CIÊNCIA E TECNOLOGIA AVÍCOLA, 2002, Campinas. Anais... Campinas: Fundação Apinco de Ciência e Tecnologia Avícolas, 2002. p.75.

SHANE, S.M. Mannan oligosaccharides in poultry nutrition: mechanisms and benefits. In: ALLTECH'S ANNUAL SYMPOSIUM, 17., 2001, Lexington. Proceedings... Lexington: Alltech, 2001. p.65-77.
SILVA, D.J.; QUEIROZ, C.A. Análise de alimentos: métodos químicos e biológicos. 3.ed. Viçosa, MG: Editora UFV, 2002. $235 p$.

SIMS, M.D.; DAWSON, K.A.; NEWMAN, K.E. et al. Effects of dietary mannan oligosaccharide, bacitracin methylene disalicylate, or both on the live performance and intestinal microbiology of turkeys. Poultry Science, v.83, n.7, p.11481154, 2004.

STATSOFT. Statistica for Windows (Computer program manual). Tulsa, 1995. (CD-ROM).

THORPE, J.; BEAL, J.D. Vegetable protein meals and the effects of enzymes. In: BEDFORD, M.R.; PARTRIDGE, G.G. (Eds) Enzymes in farm animal nutrition. Wallingford: Cabi-Publishing, 2001. p.125-144.

UNI, Z.; GANOT, S.; SKLAN, D. Posthatch development of mucosal function in the broiler small intestine. Poultry Science, v.77, n.1, p.75-82, 1998.

Van LEEUWEN, P. Significance of combined nutritional and morphological precaecal parameters for feed evaluation in non-ruminants. 2002. 153f. Thesis (Doctor in Animal Science) - Wageningen University, Wageningen, 2002.

WALDROUP, P.W.; FRITTS, C.A.; YAN, F. Utilization of Bio$\operatorname{Mos}^{\circledR}$ mannan oligosaccharide and Bioplex ${ }^{\circledR}$ copper in broiler diets. International Journal of Poultry Science, v.2, n.1, p.44-52, 2003

YASAR, S.; FORBES, J.M. Enzyme supplementation of dry and wet wheat-based feeds for broiler chickens: performance and gut responses. British Journal of Nutrition, v.84, n.3, p.297-307, 2000

ZDUNCZYK, Z.; JANKOWSKI, J.; JUSKIEWICZ, J. et al. Response of young turkeys to diets containing flavomycin, mannanoligosaccharide or inulin. Veterinarija ir Zootechnika, v.25, n.47, p.94-96, 2004.

ZENTEK, J.; MARQUART, B.; PIETRZAK, T. Intestinal effects of mannanoligosaccharides, transgalactooligosaccharides, lactose and lactulose in dogs. Journal of Nutrition, v.132, n.6, p.1682S-1684S, 2002. 